\title{
Low levels of air pollution induce changes of lung function in a panel of schoolchildren
}

\author{
H. Moshammer*, H-P. Hutter*, H. Hauck ${ }^{\#}$ and M. Neuberger*,\#
}

ABSTRACT: In search of sensitive screening parameters for assessing acute effects of ambient air pollutants in young schoolchildren, the impact of 8-h average air pollution before lung function testing was investigated by oscillatory measurements of resistance and spirometry with flowvolume loops.

At a central elementary school in Linz, the capital of Upper Austria, 163 children aged 7-10 yrs underwent repeated examinations at the same time of day during 1 school year, yielding a total of 11-12 lung function tests per child. Associations to mass concentrations of particulate matter and nitrogen dioxide $\left(\mathrm{NO}_{2}\right)$ measured continuously at a nearby monitoring station were tested, applying the Generalised Estimating Equations model.

Reductions per $10 \mu \mathrm{g} \cdot \mathrm{m}^{-3}$ (both for particles and for $\mathrm{NO}_{2}$ ) were in the magnitude of $1 \%$ for most lung function parameters. The most sensitive indicator for acute effects of combustion-related pollutants was a change in maximal expiratory flow in small airways. $\mathrm{NO}_{2}$ at concentrations below current standards reduced (in the multipollutant model) the forced expiratory volume in one second by $1.01 \%$, maximal instantaneous forced flow when $50 \%$ of the forced vital capacity remains to be exhaled (MEF50\%) by $1.99 \%$ and MEF $25 \%$ by $1.96 \%$. Peripheral resistance increased by $1.03 \%$ per $10 \mu \mathrm{g} \cdot \mathrm{m}^{-3}$ of particulate matter with a $50 \%$ cut-off aerodynamic diameter of $2.5 \mu \mathrm{m}$ (PM2.5). Resistance is less influenced by the child's cooperation and should be utilised more often in environmental epidemiology when screening for early signs of small airway dysfunction from urban air pollution, but cannot replace the measurement of MEF50\% and MEF $25 \%$. In the basic model, the reduction of these parameters per $10 \mu \mathrm{g} \cdot \mathrm{m}^{-3}$ was highest for $\mathrm{NO}_{2}$, followed by $\mathrm{PM}_{1}$, PM2.5 and PM10, while exposure to coarse dust (PM10-PM2.5) did not change end-expiratory flow significantly.

All acute effects of urban air pollution found on the lung function of healthy pupils were evident at levels below current European limit values for nitrogen dioxide. Thus, planned reduction of nitrogen dioxide emission (Euro 5; vehicles that comply with the emission limits as defined in Directive $99 / 96 / E C)$ of $20 \%$ in 2010 would seem to be insufficient.

KEYWORDS: Lung function, nitrogen dioxide, particulate matter, resistance, schoolchildren

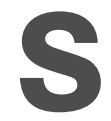
uspended particles have recently received much interest because of increasing epidemiological and experimental evidence of their health impact. Notwithstanding the fact that the exact biological mechanisms are not entirely clear, both mass and number of very fine particles have been shown to correlate with acute health effects and measurable functional changes in the cardiovascular and respiratory system [14]. Numerous panel studies investigating shortterm changes in lung function in children have been performed. Meta-analyses indicated adverse effects of ozone [5] and particulate matter [6] on lung function. However, most have focused on daily mean levels of air pollution [7] and, if investigating effect on lung function at all, have concentrated on parameters such as peak expiratory flow (PEF) that are easily collected in children.

Fine particles of different origin and chemical composition are supposed to differ in their health impact. Nitrogen dioxide $\left(\mathrm{NO}_{2}\right)$ serves as an indicator of a whole range of pollutants (including very fine particles) originating from incineration sources. Previous studies [8] on the total population of schoolchildren from Linz, the capital of Upper Austria, have shown the good predictive value of $\mathrm{NO}_{2}$ especially for maximal instantaneous forced flow when $50 \%$ of the forced vital capacity remains to be exhaled (MEF50\%) and MEF50\% in children's lung function testing.
AFFILIATIONS

*Institute of Environmental Health, Medical University of Vienna, and \#Austrian Academy of Sciences, Clean Air Commission, Vienna, Austria.

CORRESPONDENCE

M. Neuberger

Institute of Environmental Health

Kinderspitalgasse 15

A-1095 Vienna

Austria

Fax: 431427764799

E-mail: Manfred.neuberger@

meduniwien.ac.at

Received:

August 022005

Accepted after revision:

January 222006

SUPPORT STATEMENT

This study was supported by the Clean Air Commission of Austrian Academy of Science. 
The present authors had the opportunity to monitor various measures of particulate matter over the course of a joint Austrian project (Austrian Project on Health Effects of Particulates (AUPHEP)) [9] in the school year 2000-2001 at the central air monitoring site in Linz, Upper Austria. In this town of 200,000 inhabitants, with steel industry and heavy motor traffic, chronic respiratory health effects on children have been found [8] and improvements in lung function were related to improvements in air quality [10]. Current levels of particulate matter with a 50\% cut-off aerodynamic diameter of $10 \mu \mathrm{m}$ (PM10) and $\mathrm{NO}_{2}$ are in a range typical for Middle European urban areas. It was hypothesised that acute respiratory effects could still be observed on days with elevated concentrations. Therefore, the present authors chose the elementary school next to the AUPHEP monitoring station for repeated lung function testing throughout the school year. The aim of this time series study was to quantify short-term effects of air pollutants on lung functions measured by spirometry and forced oscillation technique. It was expected that peak levels of air pollution shortly before lung function testing would have the strongest impact [11, 12]. Although respirable particulate air pollution in general is known to affect lung function, previous findings [10] indicate that particulate matter from combustion (for which $\mathrm{NO}_{2}$ is a good proxy) is of prime importance.

This study had the following three aims. 1) To investigate short-term effects of air pollution on lung function (by choosing 8-h mean values instead of daily mean values for this panel study). 2) To find lung function parameters that are both sensitive to the acute impact of air pollution and suitable for screening of young schoolchildren. 3) To study these associations in an environmental setting that is typical for the current air pollution situation in many European towns.

\section{MATERIAL AND METHODS}

\section{Air monitoring}

The air of the city of Linz (located north of the Alps on the river Danube) is predominantly affected by industrial emissions (steel plant) and motor traffic (a high proportion of diesel trucks and cars) which can lead to a build up of elevated concentrations during stagnant conditions. The monitoring site, situated within a central living area, was operated between September 2000 and August 2001. The PM concentration at this site reflects the typical PM-burden in urban Linz and lies within the upper third of nine monitoring sites in and around the city. Details of the air monitoring project have been described by HAUCK et al. [9]. For this study, the half-hour mean values of PM1, PM2.5, PM10 (measured by Tapered Element Oscillating Microbalance) and $\mathrm{NO}_{2}$ (measured by chemoluminescence) were chosen to calculate the 8 -h mean values between 00:00 $\mathrm{h}$ and 08:00 $\mathrm{h}$ on all days before lung function testing was conducted.

\section{Lung function}

At the school adjacent to the monitoring station, every second day (on Monday, Tuesday, Wednesday and Friday) 20 of 164 children (aged 7-10 yrs) underwent lung function tests, so that each of the 69 female and 95 male children had spirometry approximately every fortnight at around the same time of day from September to May. Forced vital capacity (FVC), forced expiratory volume in one second (FEV1), FEV0.5, mean forced expiratory flow at 25\% (FEF25\%), FEF50\%, FEF75\% and PEF were obtained following the protocol of the American Thoracic Society [13], except for the minimum exhalation time of $6 \mathrm{~s}$, which is not feasible for children. The lung function tests were conducted between 08:30 $\mathrm{h}$ and 10:30 $\mathrm{h}$ in a fixed sequence.

Before performing routine spirometry (in the standing position), the respiratory resistance was measured (in the sitting position) using the impulse oscillation system (IOS; Erich Jaeger, Hoechberg, Germany). IOS was applied according to the producer's specifications and the resistance at oscillation frequencies between 4 and $30 \mathrm{~Hz}$ were registered [14]. To collapse these 27 data points per examination into one meaningful number, the calculated hypothetical resistance at frequency $=0(R(0, \mathrm{c}))$ was calculated as the point where a line cut the ordinate, serving as a proxy for peripheral airway resistance [15]. This line was calculated by linear regression from all data points between the frequency of 4 and the frequency with the lowest resistance.

It was planned to test each child 11-12 times. Each child was assigned to a fixed day of the week to minimise bias from weekly cycles; however, due to holidays, sick leave or other organisational problems, most of the children on 1-3 occasions had to be tested on another day of the week. Due to longer sick leave, one child could only be tested 10 times. Two children who changed school during the school year could only be tested three and six times, respectively.

\section{Statistical analysis}

Lung function values were log-transformed because multiplicative effects were expected. Sex and the logs of age, height and weight were also entered into the models as explanatory variables. The health impact of air pollution was studied applying the Generalised Estimating Equations model assuming an auto-correlation structure with lag 1 . In order to visualise the association between air pollutants and lung function, the same model was calculated without air pollution data and the residuals (of the logs of the lung function parameters) were plotted against the pollutant's concentration.

\section{RESULTS}

The 8-h mean values from 00:00-08:00 $\mathrm{h}$ included both the low concentrations of the night and the high concentrations of morning rush hour. Thus, on average, the 8-h mean levels were comparable to the daily mean levels (table 1). Annual average concentrations were mostly within current European Union (EU) and US limit values. Only PM2.5 exceeded the US limit value of $15 \mu \mathrm{g} \cdot \mathrm{m}^{-3}$ for the annual mean, but not the cap of $25 \mu \mathrm{g} \cdot \mathrm{m}^{-3}$ proposed by the European Commission in its Thematic Strategy on Air Pollution, 2005 [16]. (There is no legal limit value for PM2.5 in Europe yet.) The European PM10 limit value for the daily average $\left(50 \mu \mathrm{g} \cdot \mathrm{m}^{-3}\right)$ was exceeded on 46 days. At the time of the study, only 35 excess days were legally permitted. This noncompliance with the permitted excess days for PM10 is a problem Linz shares with most European urban areas.

The indicators of air pollution under investigation were positively and significantly correlated with each other 


\begin{tabular}{lcccc}
\hline TABLE 1 & $\begin{array}{l}\text { Concentrations of particulate matter and } \\
\text { nitrogen dioxide } \\
\text { period }\end{array}$ \\
& $\left.\mathrm{NO}_{2}\right)$ & in Linz during the study \\
Percentiles & PM10 & PM2.5 & PM1 & $\mathbf{N O}_{\mathbf{2}}$ \\
\hline 24 h mean 25\% & 16.54 & 10.46 & 8.92 & 13.75 \\
24 h mean 50\% & 25.73 & 15.79 & 13.20 & 17.50 \\
24 h mean 75\% & 37.08 & 23.07 & 19.07 & 21.48 \\
Maximum 24 h mean & 127.44 & 76.39 & 58.20 & 40.73 \\
US EPA NAAQS & 150 & 65 & & \\
EU limit values & 50 & & & \\
$\mathbf{8}$ h mean 25\% & 14.39 & 8.64 & 6.90 & 11.57 \\
$\mathbf{8}$ h mean 50\% & 24.85 & 15.70 & 12.30 & 15.49 \\
$\mathbf{8}$ h mean 75\% & 38.82 & 24.46 & 17.82 & 21.97 \\
$\mathbf{8}$ h mean-IQR & 24.43 & 25.82 & 10.92 & 10.40 \\
Annual average & 30.28 & 19.06 & 15.03 & 18.07 \\
US EPA NAAQS & 50 & 15 & & 100 \\
EU limit values & 40 & $(25)$ & & 40 \\
\hline
\end{tabular}

PMx: particulate matter with a $50 \%$ cut-off aerodynamic diameter of $x \mu \mathrm{m}$; US EPA NAAQS: United States Environmental Protection Agency National Ambient Air Quality Standards; EU: European Union; IQR: interquartile range.

(table 2). Because of the high correlation between PM1 and PM2.5, only PM2.5 was entered into the multipollutant model.

All pollutants studied in the single pollutant models had adverse effects on most of the lung function parameters. The only exceptions were FVC for the particle parameters and PEF, for which the effect estimate for $\mathrm{NO}_{2}$ did not reach significance. Overall effects were rather small. After retransforming the log values of the lung function, the changes per $10 \mu \mathrm{g} \cdot \mathrm{m}^{-3}$ or per interquartile range (IQR) were in the magnitude of $1 \%$ only. The strongest changes per IQR were seen for $\mathrm{NO}_{2}$ as a pollution indicator and, after particle exposure, for $R(0, \mathrm{c})$ as an outcome variable (table 3). (Contrary to the other lung function parameters, a positive association with the resistance indicates an adverse effect.) Dose-response relationships for $\mathrm{NO}_{2}$ are shown in figure 1, using residuals of $\log$ FEV1 (fig. 1a), MEF25\% (fig. 1b) and $R(0, \mathrm{c})$ (fig. 1c).

Coarse particles (calculated as the difference between PM10 and PM2.5) were only weakly associated with all lung function outcomes (data not shown). In the multipollutant model, together with PM2.5 and $\mathrm{NO}_{2}$, coarse particles did not exhibit any significant effect and were therefore not further investigated. Thus the multipollutant model focused on PM2.5

\begin{tabular}{llll} 
TABLE 2 & \multicolumn{3}{c}{$\begin{array}{l}\text { Correlation of ambient air pollution indicators in } \\
\text { Linz during the study period }\end{array}$} \\
\hline Pearson's $r$ of $\mathbf{8} \mathbf{h}$ means & NO $_{2}$ & PM1 & PM2.5 \\
\hline & & & \\
PM1 & 0.53 & & \\
PM2.5 & 0.54 & 0.95 & 0.93 \\
PM10 & 0.62 & 0.91 & 0.93 \\
\hline
\end{tabular}

$\mathrm{NO}_{2}$ : nitrogen dioxide; PMx: particulate matter with a $50 \%$ cut-off aerodynamic diameter of $x \mu m$. All $p<0.001$.

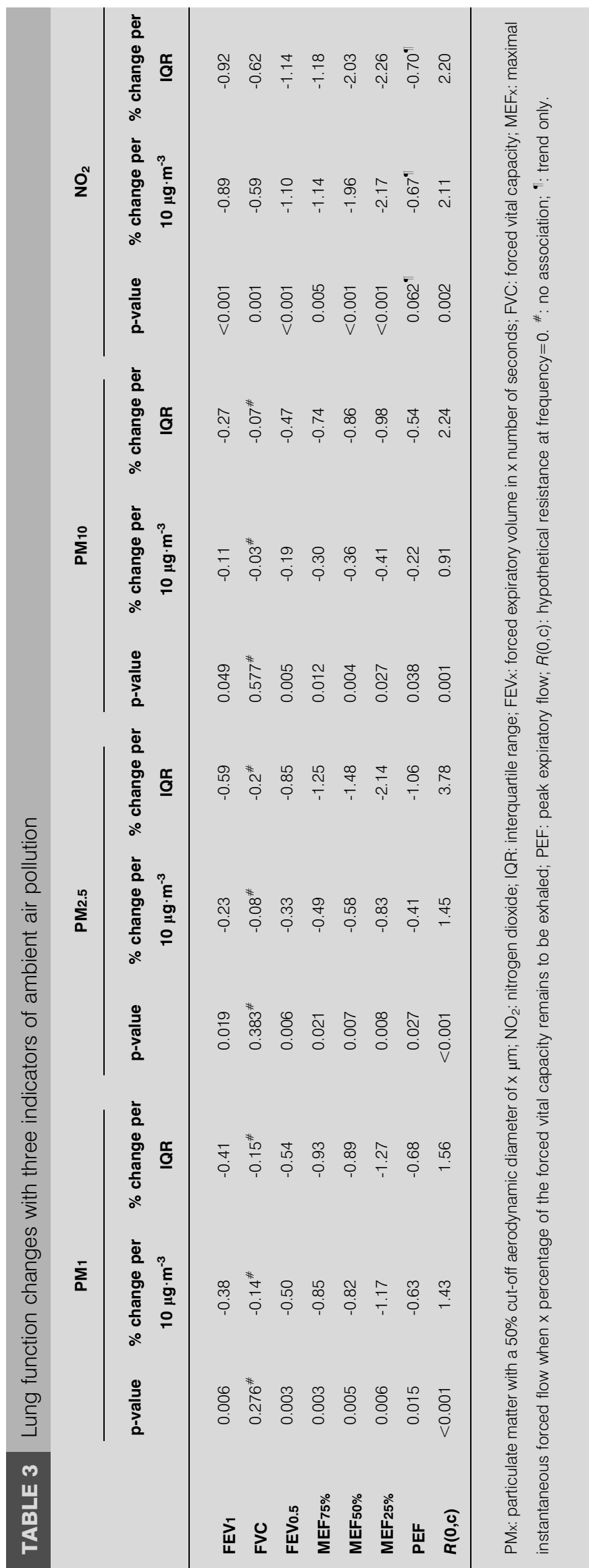



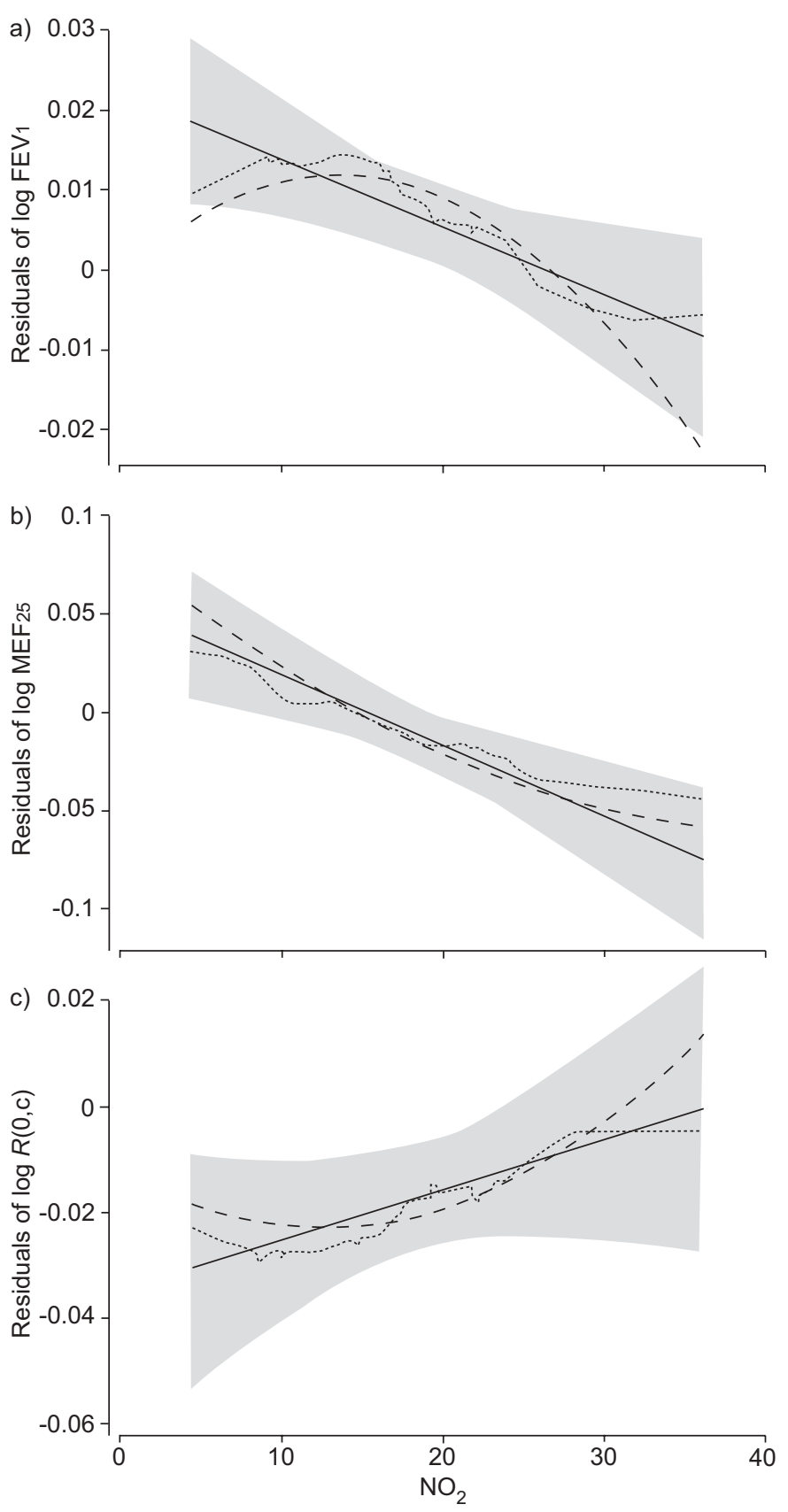

FIGURE 1. Selected outcomes for nitrogen dioxide $\left(\mathrm{NO}_{2}\right)$. Linear $(-)$ and quadratic fit $(---)$ and LOWESS plot $(\cdots \cdots \cdots)$ on the residuals of the logs of forced expiratory volume in one second ( $\left.F E V_{1}\right)$, maximal instantaneous forced flow at $25 \%$ of the forced vital capacity remaining to be exhaled (MEF25\%) and hypothetical resistance at frequency $=0(R(0, \mathrm{c}))$.

and $\mathrm{NO}_{2}$ (table 4). Most effect estimates for $\mathrm{NO}_{2}$ remained significant and some even grew larger after controlling for PM2.5. Only the effect of $\mathrm{NO}_{2}$ on PEF and $R(0, \mathrm{c})$ was reduced and no longer significant. Resistance $R(0, \mathrm{c})$, however, was influenced by PM2.5 but this was the only association with PM2.5 that remained significant after controlling for $\mathrm{NO}_{2}$.

In contrast to the morning values, the 8 -h mean values $\left(\mathrm{NO}_{2}\right.$, $\mathrm{PM})$ of the previous evening (16.00-24.00 h) were not associated with the lung function results (data not shown).

\section{DISCUSSION}

This study examined short-term effects of urban air pollution in morning hours on schoolchildren and could therefore disregard fluctuations in ozone concentrations. Earlier studies in Linz $[8,10]$ have shown relatively low ambient ozone during school years and no possibility of examining elementary schoolchildren in the afternoon and during summer vacation when ozone was higher, but children less localisable. From morning tests of lung functions during the school year, no negative associations with ozone had been found (and some positive ones were spurious and caused by the inverse relationship between ozone and $\mathrm{NO}_{2}$ ). Mean daily oxygen concentrations ranged $0.3-30.5 \mu \mathrm{g} \cdot \mathrm{m}^{-3}$ (median $4 \mu \mathrm{g} \cdot \mathrm{m}^{-3}$ ). From earlier results at higher concentrations [8], the present sulphur dioxide exposure was considered to be negligible for changes in function of small airways.

The strong correlation between the three measures of particle mass and $\mathrm{NO}_{2}$ made it difficult to separate the impact of each exposure metrically. However, in the multipollutant model, only $\mathrm{NO}_{2}$ remained consistently associated with adverse health effects. This is noteworthy because, in previous studies, $\mathrm{NO}_{2}$ was only inconsistently associated with lung function decrements [17]. This is true both for $\mathrm{NO}_{2}$ measured outdoors (where it often serves as an indicator of exposure to road traffic pollutants) and indoors (where gas cooking and unvented heaters are relevant sources). This led to the conclusion that it is not $\mathrm{NO}_{2}$ itself that causes the adverse effects, but that in many (but not all) settings it serves as a good proxy for the relevant pollution mixture. Other good proxies might be some volatile organic compounds $[18,19]$ or carbon monoxide. In the same environmental setting of Linz, $\mathrm{NO}_{2}$ also proved to be a valuable predictor of long-term lung function growth [10].

Selection bias is unlikely to play an important role in this study, which attempted to examine all children who were healthy enough to come to school. Pupils on sick leave or with a respiratory infection on the day scheduled for spirometry were tested at a later date, and all children were tested repeatedly. If children with asthma stayed at home on days with high pollution, this would lead to an underestimation of the effect on lung function.

Effects of particulate matter and $\mathrm{NO}_{2}$ on lung function decrements were in the same magnitude as reported by other studies [20]. Both LOWESS and quadratic fit (fig. 1) for FEV1 and resistance suggest a levelling off of the effect at low concentrations (at $\sim 15 \mu \mathrm{g} \cdot \mathrm{m}^{3}$ ) which could indicate a threshold. No such threshold is evident for MEF25. Small average changes on the population level can result in a relevant increase in the number of children with clinically poor lung function. Small changes are difficult to assess with spirometry in young children, because the results depend heavily on the children's cooperation. Respiratory resistance (measured with an impulse oscillation system at different frequencies) is less influenced by that. It was therefore expected to be a better indicator of small lung function changes than routine spirometric data. This expectation was met (in the single pollutant model for most parameters and in the multipollutant model for changes induced by PM2.5), and therefore it is suggested that the oscillation technique be used more frequently in future 


\begin{tabular}{|c|c|c|c|c|c|c|}
\hline & \multicolumn{3}{|c|}{ PM2.5 } & \multicolumn{3}{|c|}{$\mathrm{NO}_{2}$} \\
\hline $\mathrm{FEV}_{1}$ & $0.401^{\#}$ & $0.10^{\#}$ & $0.27^{\#}$ & $<0.001$ & -1.01 & -1.05 \\
\hline MEF $75 \%$ & $0.571^{\#}$ & $-0.15^{\#}$ & $-0.39^{\#}$ & $0.057^{\circ}$ & $-0.97^{\bullet}$ & $-1.01^{\bullet}$ \\
\hline MEF50\% & $0.868^{\#}$ & $0.04^{\#}$ & $0.11^{\#}$ & $<0.001$ & -1.99 & -2.07 \\
\hline MEF $25 \%$ & $0.596^{\#}$ & $-0.21^{\#}$ & $-0.54^{\#}$ & 0.01 & -1.96 & -2.04 \\
\hline PEF & $0.434^{\#}$ & $-0.18^{\#}$ & $-0.47^{\#}$ & $0.328^{\#}$ & $-0.44^{\#}$ & $-0.46^{\#}$ \\
\hline$R(0, e)$ & 0.004 & 1.03 & 2.69 & $0.161^{\#}$ & $0.97^{\#}$ & $1.00^{\#}$ \\
\hline
\end{tabular}

PM2.5: particulate matter with a 50\% cut-off aerodynamic diameter of $2.5 \mu \mathrm{m} ; \mathrm{NO}_{2}$ : nitrogen dioxide; IQR: interquartile range; FEVx: forced expiratory volume in $x$ number of seconds; FVC: forced vital capacity; MEFx: maximal instantaneous forced flow when $x$ percentage of the forced vital capacity remaining to be exhaled; PEF: peak expiratory flow; $R(0, c)$ : hypothetical resistance at frequency $=0$. ${ }^{*}$ : no association; $"$ : trend only.

environmental studies on children's respiratory health, particularly to assess short-term effects of PM2.5.

With regard to indicators of ambient urban air pollution as assessed at monitoring stations, the results of this study indicate that $\mathrm{PM} 2.5$ and $\mathrm{NO}_{2}$ predict early decrements of lung function in children better than PM10. Because of lower taxes for diesel compared with petrol in Austria, the number of diesel cars increased from $2.7 \%$ in 1980 to $49.2 \%$ in 2004 . Stricter emission standards and the introduction of catalysts has been counterbalanced by an increase in motor traffic and, at kerbside monitoring stations in Linz and other Austrian towns, a slight increase of $\mathrm{NO}_{2}$ has been seen in recent years. It seems unlikely that the foreseen reduction of emission concentration of only $20 \%$ in 2010 (Euro 5; vehicles that comply with the emission limits as defined in Directive 99/96/ EC [21]) will solve this problem. The findings of this study suggest that exposure levels below EU standards have a health effect and that more stringent limitations of ambient peak $\mathrm{NO}_{2}$ concentrations are necessary to prevent lung function impairment in children. Traffic-related $\mathrm{NO}_{2}$ concentrations were also associated with wheezing and asthma medication of children [22] and with long-term effects, increasing respiratory mortality by $16(6-26) \%$ per $10 \mu \mathrm{g} \cdot \mathrm{m}^{-3}$ of $\mathrm{NO}_{x}$ (where $\mathrm{NO}_{\mathrm{x}}$ is any oxide of nitrogen) [23]. These findings contribute to the evidence for the serious health effects of urban air pollution indicated by $\mathrm{NO}_{2}$ and the necessity to lower it.

The results of this lung function study also question the cap of $25 \mu \mathrm{g} \cdot \mathrm{m}^{-3}$ for concentrations of ambient particulate matter with a $50 \%$ cut-off aerodynamic diameter of $2.5 \mu \mathrm{m}$, which is proposed as annual mean by the European Commission in its Thematic Strategy on Air Pollution, 2005. In the absence of an indication for a threshold, adverse effects of urban air pollution should be reduced as much as possible by minimising emissions of primary and secondary fine particulates, especially from combustion.

\section{ACKNOWLEDGEMENTS}

The authors would like to thank the Municipality of Linz (Depts of Health and Environment) and the Austrian Project on Health Effects of Particulates (AUPHEP) team for their basic work. AUPHEP (lead by O. Preining, Austrian Academy of Sciences, Clean Air Commission, Vienna, Austria) was a project of the Clean Air Commission of the Austrian Academy of Sciences in collaboration with the Medical University of Vienna (Institute of Environmental Health, University Children's Hospital), the University of Vienna (Institute for Experimental Physics), the Vienna University of Technology (Institute for Chemical Technologies and Analytics) and Austrian Environmental Agencies (Federal and Provincial), funded by: the Ministry for the Environment, Youth and Family Affairs; Ministry for Science and Traffic; Austrian Academy of Sciences and the Ambient Air Monitoring Networks of Vienna, Lower Austria, Upper Austria and Styria, Austria. The coordinator, H. Hauck, was supported by B. Gomiscek, Organisational Sciences of University Maribor (Maribor, Slovenia).

\section{REFERENCES}

1 Penttinen $\mathrm{P}$, Timonen $\mathrm{KL}$, Tiittanen $\mathrm{P}$, Mirme $\mathrm{A}$, Ruuskanen J, Pekkanen J. Number concentration and size of particles in urban air: effects on spirometric lung function in adult asthmatic subjects. Environ Health Perspect 2001; 109: 319-323.

2 Peters A, Dockery DW, Heinrich J, Wichmann HE. Shortterm effects of particulate air pollution on respiratory morbidity in asthmatic children. Eur Respir J 1997; 10: 872-879.

3 Pope CA 3rd, Dockery DW, Spengler JD, Rainzenne ME. Respiratory health and PM10 pollution - a daily time series analysis. Am Rev Respir Dis 1991; 144: 668-674.

4 Schwartz J, Slater D, Larson T, Pierson WE, Koenig JQ. Particulate air pollution and hospital emergency visits for asthma in Seattle. Am Rev Respir Dis 1993; 147: 826-831.

5 Lippmann M. Effects of ozone on respiratory function and structure. Annu Rev Public Health 1989; 10: 49-67.

6 Dockery DW, Pope CA 3rd. Acute respiratory effects of particulate air pollution. Annu Rev Public Health 1994; 15: 107-132. 
7 Ward DJ, Ayres JG. Particulate air pollution and panel studies in children: a systematic review. Occup Environ Med 2004; 61: e13.

8 Neuberger M, Kundi M, Haider M. Combined effects of outdoor and indoor air pollution on lung functions of school children. Arch Complex Environ Studies 1995; 7: 7-11.

9 Hauck H, Berner A, Frischer T, et al. AUPHEP-Austrian Project on Health Effects of Particulates-general overview. Atmospheric Environment 2004; 38: 3905-3915.

10 Neuberger M, Moshammer H, Kundi M. Declining ambient air pollution and lung function improvement in Austrian children. Atmospheric Environment 2002; 36: 1733-1736.

11 Delfino RJ, Zeiger RS, Seltzer JM, Street DH, McLaren CE. Association of asthma symptoms with peak particulate air pollution and effect modification by anti-inflammatory medication use. Environ Health Perspect 2002; 110: A607-A617.

12 Moshammer H. Indoor- and outdoor-generated particles and children with asthma. Environ Health Perspect 2005; 113: A581.

13 American Thoracic Society. Standardization of spirometry - 1987 update. Am Rev Respir Dis 1987; 136: 1286-1298.

14 Clement J, Dumoulin B, Gubbelmans R, Hendriks S, van de Woestijne KP. Reference values of total respiratory resistance and reactance between 4 and $26 \mathrm{~Hz}$ in children and adolescents aged 4-20 years. Bull Eur Physiopathol Respir 1987; 23: 441-448.

15 Delacourt C, Lorino H, Herve-Guillot M, Reinert P, Harf A, Housset B. Use of forced oscillation technique to assess airway obstruction and reversibility in children. $A m \mathrm{~J}$ Respir Crit Care Med 2000; 161: 730-736.
16 European Commission. Thematic Strategy in Air Pollution. A communication from the Commission to the Council and the European Parliament. COM (2005) 446 final; Brussels, European Commission, September 21, 2001.

17 WHO. Effects of air pollution on children's health and development: a review of the evidence. World Health Organization Special Programme on Health and Environment, European Centre for Environment and Health, Bonn Office, 2005.

18 Delfino RJ, Gong H, Linn WS, Pellizzari ED, Hu Y. Asthma symptoms in Hispanic children and daily ambient exposures to toxic and criteria air pollutants. Environ Health Perspect 2003; 111: 647-656.

19 Delfino RJ, Gong H, Linn WS, Hu Y, Pellizzari ED. Respiratory symptoms and peak expiratory flow in children with asthma in relation to volatile organic compounds in exhaled breath and ambient air. $J$ Expo Anal Environ Epidemiol 2003; 13: 348-363.

20 Timonen KL, Pekkanen J, Tiittanen P, Salonen RO. Effects of air pollution on changes in lung function induced by exercise in children with chronic respiratory symptoms. Occup Environ Med 2002; 59: 129-134.

21 European Commission. Proposal for a Directive of the European Parliament and of the Council on the promotion of clean road transport vehicles; COM (2005). 634 final; Brussels, European Commission, December 21, 2005.

22 Gauderman WJ, Avol E, Lurmann F, et al. Childhood asthma and exposure to traffic and nitrogen dioxide. Epidemiology 2005; 16: 737-743.

23 Nafstad P, Håheim LL, Wisløff T, et al. Urban air pollution and mortality in a cohort of Norwegian men. Environ Health Perspect 2004; 112: 610-615. 